УДК 622.7

В.Г. Григорьева /к.т.н./,

В.В. Батареев /к.т.н./,

А.В. Сорокин
Криворожский металлургический институт Национальной металлургической академии Украины, г. Кривой Рог, Украина

\title{
АКТИВИЗАЦИЯ СГУЩЕНИЯ ШЛАМОВ КАК СПОСОБ СНИЖЕНИЯ ПЛОЩАДЕЙ ХВОСТОХРАНИЛИЩ
}

V.H. Hryhorieva /Cand. Sci. (Tech.)/, V.V. Batareyev/Cand. Sci. (Tech.)/, A.V. Sorokin
Kryvyi Rig Metallurgical Institute of the National Metallurgical academy of Ukraine, Kryvyi Rig, Ukraine

\section{ACTIVATING THE CONTAINMENT OF SLUDGE AS A METHOD OF REDUCING THE AREAS OF TAILING DUMPS}

Цель. На основе анализа условий образования, сбора и транспортирования значительных объемов шламов к месту их складирования (хвостохранилищам) рассмотрена возможность значительного сокращения площадей хвостохранилищ, а также инфильтрации иламов вглубь грунтов и их загрязнения неорганическими веществами.

Методика. В основу методики положен анализ физики процесса устойчивого разделения шламов на твердую и жидкую составляюшую и активизации прочесса осаждения частии, содержащиихся в шламовой суспензии как в статическом ее состоянии (при хранении в шламохранилищах), так и при движении шламов от места образования к месту хранения.

Результаты. Получены и обоснованы закономерности для вычисления скорости осаждения твердой фазы шламов как в статике, так и в движении на основе влияния на осаждение исходной концентрации твердых частии и динамической вязкости воды.

Научная новизна работы заключается в том, что получено выражение для определения скорости осаждения зависимости от гидродинамического сопряжения движения частии в направлении поперек потока жидкости в зависимости от вида потока, определяемого числом Рейнольдса.

Практическая ценность состочт в том, что получена скорость осаждения твердой фазы иламов в статике и динамике в результате влияния концентрации твердых частии и динамической вязкости водьл.

Ключевые слова: иламовая суспензия, вязкость среды, скорость осаждения, активизация прочесса, динамическая вязкость.

DOI: $10.34185 / 0543-5749.2019-5-6-41-46$

Постановка проблемы. Интенсификация скорости осаждения с одновременным уменьшением площади шламохранилища и увеличением начальной высоты шламов в хранилище; поиск условий полного улавливания твердой части шламов с исключением использования шламохранилищ.

Методика исследований. Изложение основного материала. В настоящее время применяемые технологии обогащения полезных ископаемых с использованием на конечной стадии магнитной сепарации предполагают высокие расходы технической воды, достигающие $4,5 \ldots 5,5 \mathrm{~m}^{3}$ на одну тонну обогащенной руды (концентрата), которая в смеси с твердыми отходами магнитной сепарации формирует шлам.

Образование таких объемов шламов предполагает значительные затраты на их перемещение к месту их складирования - хвостохранилищам.

На крупных металлургических предприятиях полного цикла (например, ПАО «Арсе- 
лорМиттал Кривой Рог») функции хвостохранилищ совмещают с соответствующими функциями шламохранилищ, в которых складируются и подготавливаются к последующей утилизации продукт, образующийся при уборке помещений и оборудования технологических цехов, и породная часть отходов процесса обогащения $[1,2]$.

Особенностями механических смесей хвостов и шламов (пульп) является низкая концентрация в них твердой составляющей. При взаимодействии такой смеси с дном искусственной или естественной емкости, в которую она сливается, происходит ее инфильтрация, проникновение по естественным порам вглубь грунта, загрязнение его неорганическими веществами. При этом, после 2-3-х летнего взаимодействия грунта с искусственно введенной в него взвесью физико-биологические свойства грунта деградируют и его полноценная рекультивация становится невозможной (под рекультивацией мы подрозумеваем способность использования участков земли в сельском хозяйстве по завершению их использования для складирования пульп).

Ограничение площадей, отводимых под технологические водоемы - отстойники - возможно при увеличении энергетики процессов осаждения смесей, при этом, площадь участков земли, занимаемой под остойники, может существенно уменьшаться. Скорость осаждения, при этом, должна быть увеличена пропорционально уменьшению используемой площади.

Проведенные нами экспериментальные исследования показали, что значительное уменьшение площадей, отводимых под отстойники, может быть достигнуто при генерации вибрационного поля в толщу среды (шламов, суспензии) на поверхности шламохранилища от вибрирующей поверхности, перемещаемой по зеркалу хранилища.

Основным видом силового воздействия на твердые частицы в процессе осаждения является действие сил тяжести, а также отстаивание и осаждение под действием центробежных сил циклонный процесс.[3]

Отстаивание применяют в промышленности для сгущения суспензий или их классификации по фракциям твердых частиц, а также для разделения эмульсий. Ввиду малой движущей силы (силы тяжести) в процессе отстаивания, с достаточной эффективностью возможно отделять только крупные частицы. Именно этот способ осветления рудничных и технологических вод применяется на криворожских добывающих и перерабатывающих минеральное сырье предприятиях. Достоинством отстаивания являются ми- нимальные удельные затраты энергии на процесс.

Очевидно, уменьшение площадей, отведенных под технологические водоемы - отстойники - возможно только при увеличении энергетики процесса осаждения взвесей. Наиболее эффективный способ управления энергетикой процесса осаждения - создание поля центробежных сил в суспензии. Таким образом, активизация процесса осаждения частиц, содержащихся в суспензии при непрерывном ее движении, возможна только при поддержании вращательного движения ее потока с заданными геометрическими и скоростными характеристиками.

Центробежный эффект можно создать либо заставляя поток жидкости протекать по витому каналу определенной кривизны и шероховатости (циклонный процесс), либо посредством пропускания потока жидкости через вращающуюся емкость (процесс центрофугования).

Физика процесса устойчивого разделения в поле центробежных сил вращением при угловой скорости $\omega$, определяется равенством сил гидродинамического сопротивления осаждаемой частицы и центробежной силы.

Будем считать, что в плоскости разделения не действует сила тяжести (вращение потока происходит вокруг его центральной вертикальной оси). Сила инерции, действующая при этом на упомянутый поток, с учетом влияния Архимедовой силы относится к силам объемного действия. Тогда на частицу действует следующая нормальная разделяющая сила $N:$ [4]

$$
N=\frac{\pi d^{3}}{6} \cdot \omega^{2} r\left(\rho_{h}-\rho_{v}\right),
$$

где $d$ - размер частицы; $r$ - радиус вращения частицы в потоке жидкости; $\rho_{h}-$ плотность тела частицы; $\rho_{v}-$ плотность жидкости; $\omega-$ угловая скорость вращения жидкости, содержащей частицу.

Сила сопротивления установившемуся осаждению частицы по радиальному направлению зависит от мидельной площади частицы и составит:

$$
R=c_{x} \frac{\pi d^{2}}{4} \cdot \frac{\rho_{v} \cdot v^{2}}{2}
$$

где $c_{x}$ - эмпирический коэффициент сопротивления движению частицы; $v$ - скорость установившегося осаждения частицы в жидкости.

Установившийся процесс осаждения в поле центробежных сил, определяется балансом разделяющей силы и силы сопротивления:

$$
N-R=0 .
$$


После соответствующей постановки получаем уравнение:

$$
\frac{\pi d^{3}}{6} \cdot \omega^{2} r\left(\rho_{h}-\rho_{v}\right)=c_{x} \frac{\pi d^{2}}{4} \cdot \frac{\rho_{v} \cdot v^{2}}{2} .
$$

Из уравнения (3) определяется скорость осаждения под действием центробежной силы с учетом силы Архимеда:

$$
v=\omega \sqrt{\frac{4}{3} \cdot \frac{d}{c_{x}} \cdot r \cdot\left(\frac{\rho_{h}}{\rho_{v}}-1\right)} .
$$

Основная трудность при вычислении скорости осаждения по формуле (4) состоит в том, что в нее входит коэффициент гидродинамического сопротивления движению частицы в направлении поперек потока жидкости (осаждение происходит поперек потока). Этот коэффициент носит эмпирический характер и зависит от вида потока, обтекающего движущуюся частицу. При ламинарном обтекании этот коэффициент меньше, чем при турбулентном, и определяется критерием режима движения (числом Рейнольдca):

$$
\operatorname{Re}=\frac{v \cdot d \cdot \rho_{v}}{\mu_{v}},
$$

где $\mu_{v}$ - коэффициент динамической вязкости воды.

Коэффициент динамической вязкости зависит от температуры воды $\left(t,{ }^{\circ} \mathrm{C}\right)$ и концентрации твердых частиц в пульпе.

Экспериментальные данные показывают, что зависимости коэффициента сопротивления от концентрации в пульпе твердых частиц:

- при числе Рейнольдса Re $\leq 1,85$

$$
c_{x}=\frac{24}{\operatorname{Re}} ;
$$

- при числе Рейнольдса $1,85<\operatorname{Re}<500$

$$
c_{x}=\frac{18.5}{\operatorname{Re}^{0.6}}
$$

- при числе Рейнольдса $\operatorname{Re} \geq 500$

$$
c_{x}=0.44 .
$$

Очевидно, для мелких частиц, крупностью в несколько микрон, от которых требуется осветлить техническую воду $\left(\operatorname{Re} \approx 5 \cdot 10^{-5}\right)$, применимо выражение (6-a). В таком случае выражение (4) преобразуется до вида:

$$
v=\frac{d^{2}}{18 \mu_{v}} \cdot \omega^{2} \cdot r \cdot\left(\rho_{h}-\rho_{v}\right) .
$$

Таким образом, при осветлении технологических вод посредством поля центробежных сил скорость осаждения зависит от диаметра частицы, угловой скорости вращательного движения потока, несущего частицу, и от радиуса вращения частицы.

Анализ (7) показывает, что для осаждения минеральных частиц, применение циклонного метода рационально только для размеров частиц $\mathrm{d}>350 \ldots .500$ мкн.

Зависимость скорости осаждения частиц размером $1,5,10,100$ мкн в зависимости от частоты вращения рабочего органа радиусом 1 м показана на рис. 1.

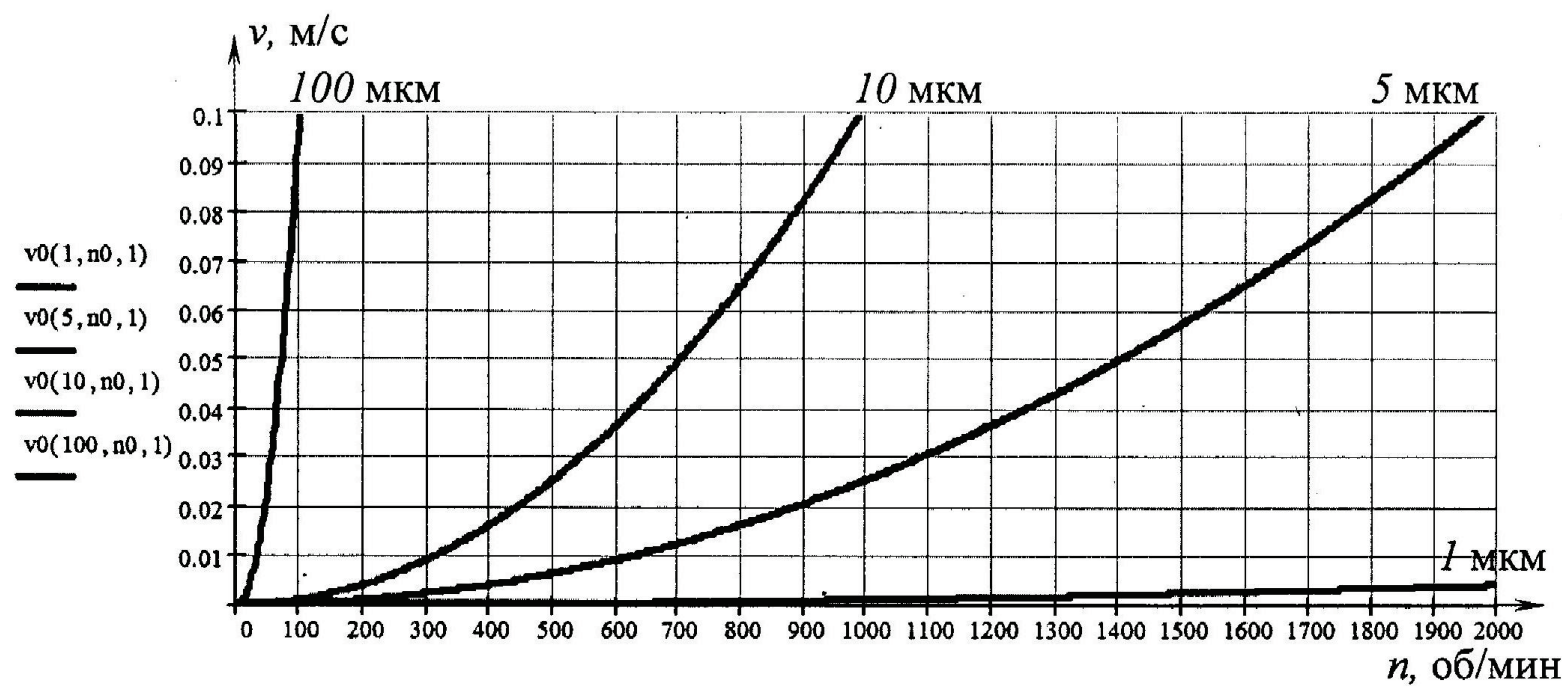

Рис. 1. Зависимость скорости осаждения частиц на рабочем органе радиусом 1 м от частоты вращения центрифуги в зависимости от крупности частиц 
На рис. 2 показана зависимость времени осаждения частиц размером 50 микрон, при радиусе вращающейся емкости с шламом 1 метр, от частоты вращения рабочего органа.

На рис. 3 показана зависимость длины рабочего органа центробежного осадительного аппарата при осевой (аксиальной) скорости протекающего потока шлама $1 \mathrm{~m} / \mathrm{c}$ и различной тол- щины потока $(0.1,0.2, \ldots, 0.5$ м) для частиц размером 50 микрон от частоты вращения рабочего органа.

При толщине слоя воды 0.5 м и ее аксиальной скорости 1 м/с производительность устройства составляет около $3 \mathrm{~m}^{3} / \mathrm{c}$.

Разделение твердых частиц в толще потока в процессе перемещения смеси по изгибу трубопровода показано на рис. 4.

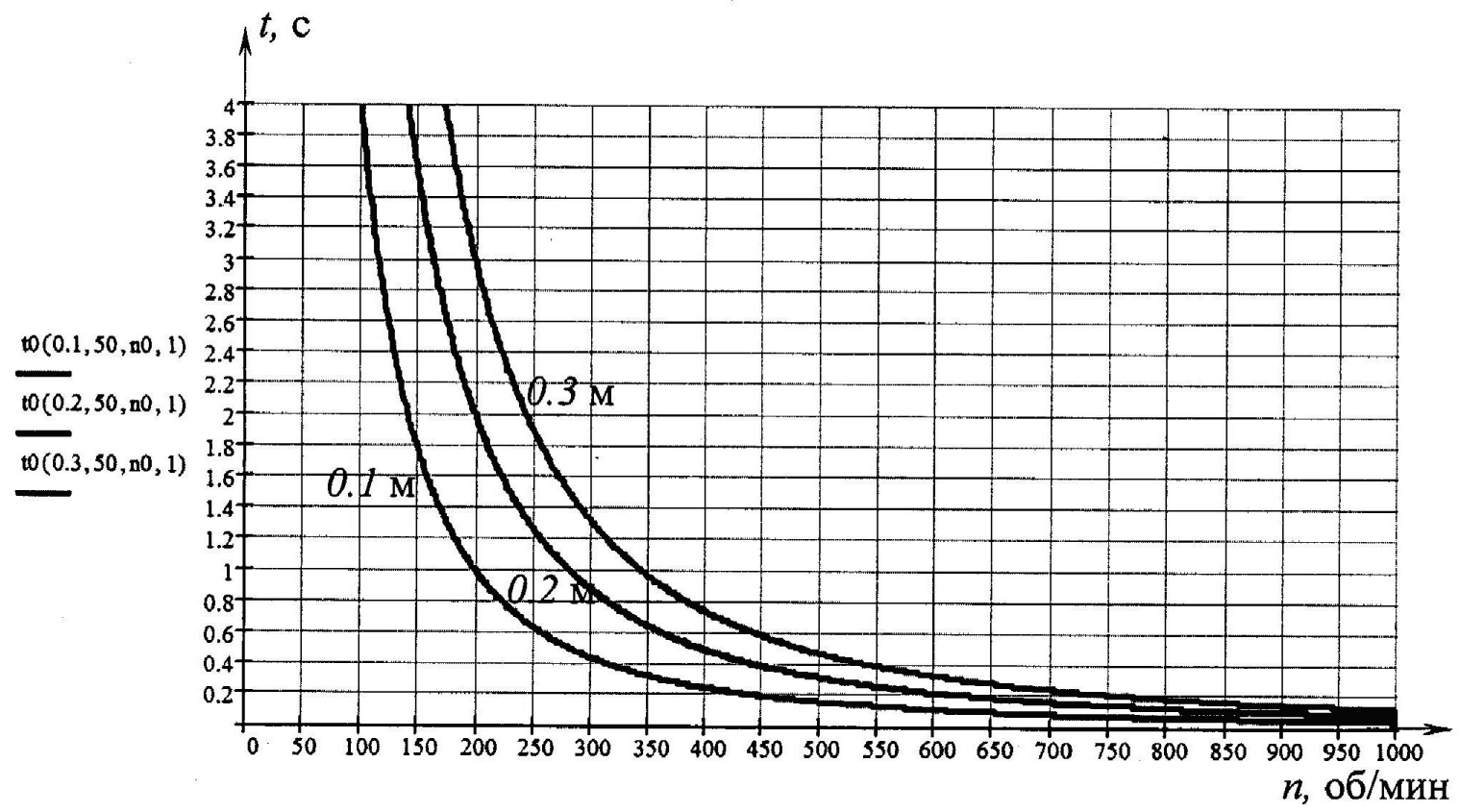

Рис. 2. Зависимость времени осаждения частиц на рабочем органе радиусом 1 м от частоты вращения центрифуги при различной толщине слоя воды в ней

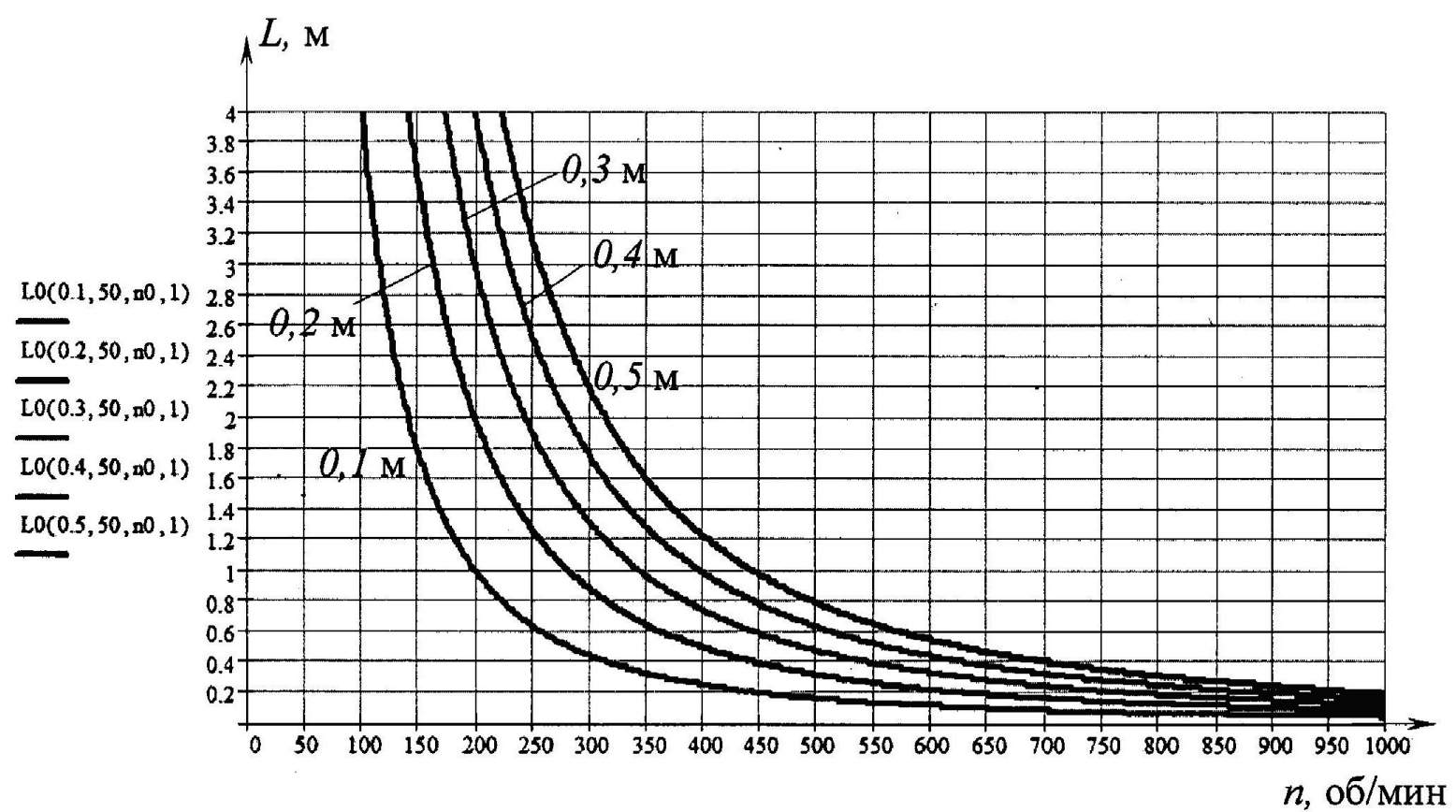

Рис. 3. Зависимость длины рабочего органа радиусом 1 м от частоты вращения центрофуги при различной толщине слоя воды в ней 


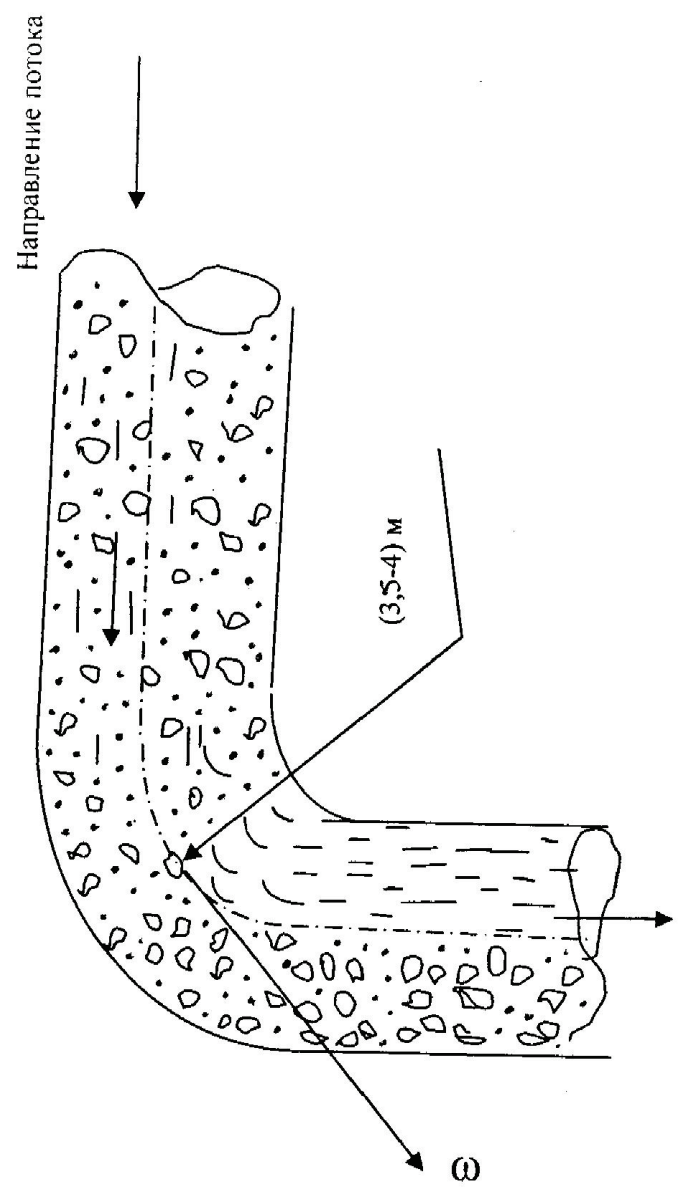

Рис. 4. Сегрегация твердых частиц в потоке

Выводы и перспективы развития направления. Установлено, что скорость осаждения частиц в их смеси с водой зависит от размера частиц и концентрации смеси: чем выше размер частиц, тем большая скорость осаждения; чем выше концентрация частиц в неньютоновской жидкости, тем меньше скорость осаждения.

Показано, что установленные зависимости являются нелинейными, т.е. механическая смесь воды с мелкими частицами, формирующими шлам, может быть представлена как неньютоновская жидкость.

Создана система интенсивного осаждения твердой части шламов на прицеховой территории с замкнутым циклом возврата твердой части шламов в агломерационную шихту, а воды - во внутрицеховой водооборот.

\section{Библиографический список}

1. Медведева О. А. Хвостохранилища Кривбасса, проблемы и особенности их эксплуатации. Геотехническая механика. 2012. Вып. 103. C. 279-285.

2. Перспективы вовлечения в эксплуатацию техногенных месторождений (на примере Ук- раины и Грузии)/ П. И. Копач и др. Екологія $i$ природокористування. 2013. Вип. 16. С. 210217.

3. Малиновская Т. А., Кобринский И. А., Кирсанов О. С., Рейнфарт В. В. Разделение суспензий в химической промышленности. Москва : Химия, 1983. 264c.

4. Дытнерский Ю. И. Процессы и аппараты химиеской технологии : учебник для вузов. Изд. 2-е. В 2-х кн.: Часть 1. Теоретические основы процессов химической технологии. Гидромеханические и тепловые процессы и аппараты. Москва : Химия, 1995. 400 с.

5. Курс физики: Учебник для вузов: В 2 т., Т. 2, 2-е изд., испр./ Под ред. В. Н. Лозовского. СПб. : Лань, 2001. 576 с.

\section{References}

1. Medvedeva, O. A. (2012). Hvostohranilishcha Krivbassa, problemy i osobennosti ih ekspluatatsii. Geotehnicheskaya mehanika, 103.

2. Kopach, P. I., Yakubenko, L. V., Romanenko, V. N. et al. (2013). Perspektivy vovlecheniya v ekspluatatsiyu tehnogennyh mestorozhdenij (na primere Ukrainy i Gruzii). Ekologiya i pryrodoko- 
rystuvannya. 16.

3. Malinovskaya, T. A., Kobrinskiy, I. A., Kirsanov, O. S., \& Reinfart, V. V. (1983). Razdelenie suspenziy $v$ himicheskoj promyshlennosti. Moskva: Himiya.

4. Dytnerskij, Y. I. (1995). Protsessy i apparaty himicheskoj tehnologii. Vol. 1. Teoreticheskie osnovy protsessov himicheskoj tehnologii. Gidromehanicheskie i teplovye protsessy i apparaty. Moskva: Himiya.

5. Lozovskiy, V.N. (Ed.). (2001). Kurs fiziki. Vol. 2. SPb.: Lan.

Мета. На основі аналізу умов утворення, збору і транспортування значних обсягів шламів до місия їх складування (хвостосховища) розглянута можливість значного скорочення плоч, хвостосховищ, а також інфільтрації иламів вглиб грунтів та їх забруднення неорганічними речовинами.

Методика. В основу методики покладено аналіз фізики процесу стійкого поділу иламів на тверду і рідку складову і активізації процесу осадження частинок, шо містяться в шламової суспензї̈ як в статичному ї̈ стані (при зберіганні в шламосховищах), так $і$ при русі шламів від місия утворення до місия зберігання.

Результати. Отримані і обгрунтовані закономірності для обчислення швидкості осадження твердої фази иламів як в статиці, так i в русі на основі впливу на осадження вихідної концентрації твердих частинок $і$ динамічної в'язкості води.

Наукова новизна роботи полягає в тому, щуо отримано вираз для визначення швидкості осадження залежності від гідродинамічного сполучення руху частинок в напрямку поперек потоку рідини в залежності від виду потоку, щзо визначається числом Рейнольдса.

Практична цінність полягає в тому, щчо отримана швидкість осадження твердої фази иламів в статиці і динаміці в результаті впли- ву концентрації твердих частинок $і$ динамічної в'язкості води.

Ключові слова: иламова суспензія, в'язкість середовища, швидкість осадження, активізація прочесу, динамічна в'язкість.

Purpose. The possibility of considerable reduction of tailing dumps areas and infiltration of sludge deep into the ground and their pollution by inorganic substances was considered in this article. This possibility was based on the analysis of the circumstances of formation, assembly and transportation of significant sludge volume to the place of their storage (tailing dumps).

Methods. The methodology is based on analysis of physics of the process of sustainable sludge separation into the solid and liquid components and enhancing the particle deprecation process. The particles were found in the slurry suspension in its static state (when stored in a sludge storage), as well as insludge moving from the place of formation to the place of storage.

Results: Regularities for calculating the sedimentation rate of the solid phase of slimes both in statics and in motion based on the influence on the deposition of the initial concentration of solids and dynamic viscosity of water are obtained and substantiated here.

Originality of the work is in getting expression to determine the speed of deposition dependences on the hydrodynamic conjugation of particle motion in the direction across the fluid flow depending on the type of flow determined by the Reynolds number.

Practical implications is in obtaining the deposition rate of solid phase sludge in statics and dynamics as a result of influence of solid concentration and dynamic viscosity of water.

Keywords: slurry suspension, environmental viscosity, deposition rate, process activation, $d y$ namic viscosity. 